\title{
The Obligations of an Anchored Vessel to Avoid Collision at Sea
}

\author{
Pengfei Zhang ${ }^{1}$ and Jinsong Zhao ${ }^{2}$ \\ ${ }^{1}$ (Merchant Marine College, Shanghai Maritime University, China) \\ ${ }^{2}$ (Koguan Law School, Shanghai Jiao Tong University, China) \\ (E-mail: Pengfei.Zhang@greenwich.ac.uk)
}

\begin{abstract}
When a collision occurs between two ships on the high seas, very likely one may need to determine who should be liable for the collision and the apportionment of liability between them. However, it is not unusual to see a collision between an anchored vessel and another vessel underway. When determining apportionment of liability between them, it seems that there is a presumption of fault against the vessel underway. To counteract such a presumption, the author discusses some issues in respect of collisions between a vessel at anchor and others underway under the International Regulations for Preventing Collisions at Sea, 1972 (COLREGs) by examining the obligations of anchored vessels to avoid a collision at sea.
\end{abstract}

\section{KEY WORDS}

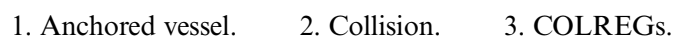

Submitted: 11 December 2012. Accepted: 14 February 2013. First published online: 22 March 2013.

1. INTRODUCTION. Among the many navigational processes involved in operating a vessel of any size, anchoring is extremely important. That is, the use of the vessel's anchor(s) as a control mechanism in a variety of different situations, including as a measure to avoid collision. Relatively little attention has been given to this subject in the academic literature. Collision between a vessel at anchor and a vessel underway is bound to occur from time to time during the navigation and operation process. However, there are no direct or clear rules in the International Regulations for Preventing Collisions at Sea, 1972, as amended (COLREGs) regarding the obligations of anchored vessels to avoid collision. Whether or not an anchored vessel had an obligation to avoid collision will be directly related to liability apportionment issues when a collision occurred. In many cases, during the collision liability apportionment between an anchored vessel and a vessel underway, it seems that there is always the presumption that the vessel underway shall be apportioned most, if not all, of the liability before conducting a detailed analysis. To some extent, this mistaken thinking leads to inertia which results in the anchored vessel taking no, or negative, action when the risk of a collision arises. As a matter of good seamanship, a vessel underway would be expected to keep clear of an anchored vessel. However, a vessel at anchor should not completely rely on other vessels to keep clear of her. In some circumstances, an anchored vessel should also take decisive action to avoid immediate collision. 


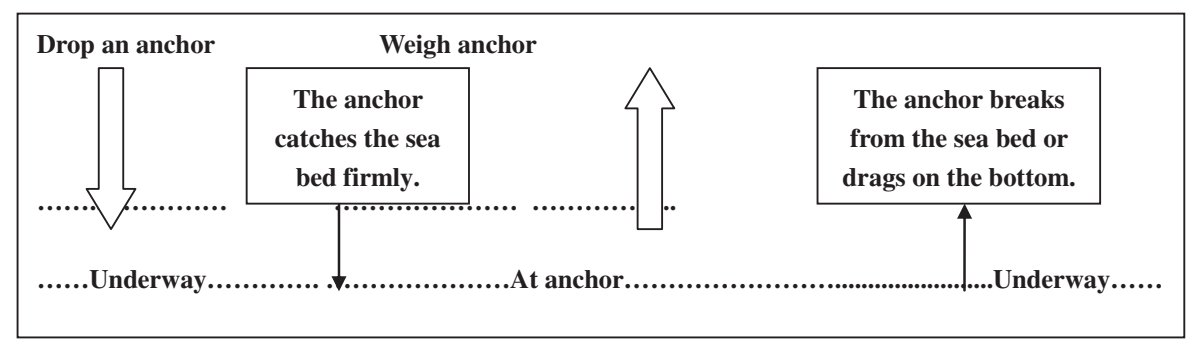

Figure 1. The transition between "underway" and "at anchor".

2. THE CONCEPT OF A VESSEL AT ANCHOR. A ship is deemed to be anchored when she is held in position by an anchor attached to the bottom of a body of water (Dodge and Kyriss, 1981). During some ship handling operations, anchors are frequently used to prevent a ship from drifting away from a desired position by lowering an anchor to the sea bed by a length of chain cable (House, 2007). There are many occasions when it is necessary for a vessel to use anchors such as: anchoring when waiting for a berth; anchoring during heavy weather conditions; anchoring when receiving fuel oil; anchoring when loading and unloading cargo and anchoring for maintenance purposes. It is stated in Rule 3(i) of the COLREGs that '[T] he word "underway" means that a vessel is not at anchor, or made fast to the shore, or aground'. In effect, the condition 'underway' is defined. However, the COLREGs do not make it clear what kind of status is defined by the term 'at anchor' but only enumerate the four states of 'motion' of a vessel.

There are commentators who consider that 'at anchor', under COLREGs, means a condition where the anchor flukes hold the sea bed firmly and the vessel is secured in a specific position (Chen, 1997; Wang, 1994). In the case of the Palembang, the Judge adopted a criterion to determine whether a vessel was at anchor or not. The criterion required that a vessel at anchor must actually be held by, or under the control of, her anchor. The moment she ceases to be so, she is in the category of a vessel underway (Palembang, The, 1929). During an anchoring operation, the ship's state of motion changes between 'underway' and 'at anchor'. The anchored state begins when the anchor flukes catch the sea bed firmly and the vessel is maintained in a specific position. The vessel is considered to be 'underway' as soon the anchor is aweigh or dragging on the bottom of the sea. In the case of the Romance the Judge determined that the vessel was still in the anchored state if the vessel winds the anchor but it has not broken from the soil. In the Forest Lake case the Judge held that once the anchor leaves the soil, the vessel shall lower the anchor ball and turn on the navigation lights immediately. As shown in Figure 1, when the anchor catches, and breaks from, the sea bed then the ship's motion status changes between "underway" and "at anchor".

A vessel is in the underway state even when she is stopped and making no way through the water (IMO, 1982). In recent years Dynamic Positioning (DP) systems have been widely used to maintain a vessel's position and heading through the co-ordinated control of its own thrusters (House, 2000). The ability of a DP system is to hold a vessel in its desired position automatically without the use of physical restraints (Daniel, 1984). Therefore, a vessel operating in DP mode is underway if she is not connected to the bottom of the sea by cables and anchors. By contrast, if a vessel uses a DP system in combination with anchoring to maintain a position, and the 
anchor is secured to the sea bed firmly, she should be deemed to be in an anchored state. Similarly, a vessel being towed up to her anchor has been said to still be an anchored vessel so long as her anchor has not broken out of the sea bed (Romance, The, 1901). However, a vessel which is dragging an anchor to prevent sheering in narrow waters, or loses control of her anchor, is deemed not to be an anchored vessel. A dredger which is operating with her anchor dragging on the bottom is also categorized as a vessel underway.

\section{OBLIGATIONS BEFORE A RISK OF COLLISION EXISTS.}

Before entering the area for anchoring, traffic density, visibility and the proximity to navigation hazards should be fully assessed by the vessel (House, 2012). When she anchors, the availability of sea room, especially to leeward, should be observed; she must not stay too close to other anchored vessels and endanger other vessels which may be navigating close by (Cockcroft, 2012). The anchorage location she selects must avoid encroaching on the foreseeable swinging circle of vessels anchored nearby. If one vessel anchors near another anchored vessel, the space left between them for swinging should be sufficient that in ordinary circumstances the two vessels cannot come together (Diomed, The, 1946). In the meantime, sufficient cable must be put out according to circumstances and a second anchor should be used if necessary (Juniata, The, 1903). The state of the weather, with particular attention to wind, current and tides, should be kept under continual observation. A second anchor should be deployed immediately to guard against dragging if there is doubt about the holding power of a single anchor, of if there is insufficient sea room to pay out more anchor chain (Allen, 2005). A vessel coming to anchor must act promptly in taking down her navigation lights and substituting anchor lights or shapes according to COLREGs (Griffin, 1949). It is incorrect for a vessel at anchor even for a very short time to exhibit the wrong lights and black balls (Lehigh, 1935). The failure to display the lights of the required character and location will of course make the anchored vessel liable for a collision (Oliver, 1885). In dense fog and restricted visibility, special sound signals are also required under COLREGs to warn ships in vicinity. In addition, a vessel at anchor is still considered 'at sea'. As such, an effective and proper watch, or watches, must continue to be kept at all times to: verify the vessel's anchor position and proper operation of the vessel's lights and whistle signals; veer additional chain; detect a dragging anchor and take reasonable measures upon the approach of another vessel. The duty officer should have all relevant information and maintain an anchor watch adequate for the foreseeable circumstances and conditions. The second anchor, the main engine and the power to the windlass should be prepared for emergency operation if the circumstances require.

\section{OBLIGATIONS AFTER A RISK OF COLLISION EXISTS. In} order to avoid a collision where another vessel is bearing down on her anchored position, an anchored vessel should be prepared to take reasonable action where the specific circumstances require (Prospector, The, 1958). It is not unusual for vessels to share a common anchorage. In the event that there is another vessel dragging anchor towards his vessel, the officer on duty should inform the Master immediately. In the meantime, actions should be taken to draw the attention of the 
other vessel in case the incident has not been detected such as making ready own engines and sending forward the crew to weigh up the anchor (Danton, The, 1996). The situation where a vessel not under command (NUC) approaches your vessel is similar. The NUC vessel is at the mercy of winds and the seas, therefore she is not able to carry out a manoeuvre to prevent the collision (Salinas et al., 2012). For the anchored vessel, action which can be taken is very limited and dependent on the time available. If time is ample, the anchored vessel should be prepared to weigh anchor and shift anchorage location to another place. In the case that time is very limited, in conjunction with working her helm, the anchored vessel with power ready can, and should, use her engines to assist avoiding a collision. The failure to do that will make the anchored vessel liable for a collision (Sabine, The, 1974). For the vessel underway, it is obviously her bounden duty to keep clear of the anchored vessel, even when the vessel is in a fairway or elsewhere at an improper position. However, the anchored vessel still may be held at fault for a collision due to her obstinate refusal to move from her anchorage where she necessarily endangers the underway vessel that is alone unable to avoid collision (Defender, The, 1921). In this case, the anchored vessel is obliged to do what she can to assist the underway vessel to clear her, either by using her engines, sheering her helm, paying out chain or in any other way possible, and failure to do so may be held to be negligence (Gault, 2003).

5. CONCLUSION. This article attempts to provide a comprehensive overview of the obligations expected of a vessel at anchor by showing that the concept of an 'anchored vessel' is more complicated than it might appear at first sight. While recognizing that an anchored vessel is at a distinct disadvantage in its ability to manoeuvre, it is nevertheless considered that good seamanship demands that she must follow a number of risk management practices. Based on the principles and good seamanship requirements of the International Regulations for Preventing Collisions at Sea, 1972, as amended (COLREGs), the anchored vessel is still required to take active and positive measures, depending upon the specific circumstances, to avoid a collision. The discussion suggests that there are a number of obligations imposed on an anchored vessel. The anchored vessel should be properly positioned, adequately lit at night and exhibit an anchor ball by day. Furthermore, the anchored vessel must, at all times, maintain an effective and proper watch and be well-prepared for emergency operations. Thereafter, the anchored vessel has a duty to take reasonable measures to avoid a collision where the specific circumstances require.

\section{ACKNOWLEDGEMENT}

The authors wish to acknowledge the assistance of Scott Richard in checking the usage and phraseology used in this text.

\section{REFERENCES}

Allen, C. H. (2005). Farwell's Rules of the Nautical Road, $8^{\text {th }}$ Edition. Annapolis, Naval Institute Press, 103-104. 
Chen, Y. P. (1997). A Discussion on the Concept and Correct Handling of Anchor. Navigation of Tianjin. 2, 1-2.

Cockcroft, A. N. and Lameijer, J. N. F. (2012). A Guide to the Collision Avoidance Rules, $7^{\text {th }}$ Edition. Oxford, Elsevier, 3-4.

Daniel, J. J. S. (1984). Dynamic Positioning Systems. The Journal of Navigation, 37, 264-270.

Danton, G. (1996). The Theory and Practice of Seamanship, $11^{\text {th }}$ Edition. London, Routledge, 18-20.

Defender, The (1921). 6 LI. L., Rep. 392.

Diomed, The (1946). 79 LI. L., Rep. 526.

Dodge, D. O. and Kyriss, S. E. (1981). Seamanship: Fundamentals for the Deck Officer. Annapolis, United States Naval Institute, 182.

Gault, S. (2003). Marsden on Collisions at Sea. London, Sweet \& Maxwell Limited.

Griffin, J. W. (1949). The American Law of Collision. Baltimore, American Maritime Cases, 257.

House, D. J. (2000). Command Companion of Seamanship Techniques, Vol. 3. Oxford, Elsevier Ltd., 168-170.

House, D. J. (2007). Ship Handling: Theory and Practice. Oxford, Elsevier Ltd., 65-67.

House, D. J. (2012). Seamanship Techniques: Shipboard and Marine Operations, $3^{\text {rd }}$ Edition. Oxford: Routledge, 51-52.

IMO [International Maritime Organization]. International Regulations for Preventing Collisions at Sea, 1972, with amendments adopted from December 2009. IMO Publications, London.

IMO [International Maritime Organization] (1982). IMO MSC Circular 332 - Guidance for the Uniform Application of Certain Rules of the 1972 Collision Regulations. IMO Publications, London.

Juniata, The (1903). Eastern District Court of Virginia, 124F, 861.

Lehigh, The (1935). A.M.C. 1546, 12F, Supp. 75.

Oliver, The (1885), V.22 Federal Reporter, 848.

Palembang, The (1929). Probate Division LRPD. 246, (1929) 34 LI. L., Rep., 107. PDAD.

Prospector, The (1958). 2 Lloyd's Rep. PDAD, 288.

Romance, The (1901). Probate Division LRPD, 15.

Sabine, The (1974). 1 Lloyd's Rep., 465, 473.

Salinas, C. F., Peña, V., Pérez, G. and Horton, T. L. (2012). Not Under Command. The Journal of Navigation, 65, 753-758.

Wang, Z. M. (1994). Discussion on the status of vessel motion under 'COLREGs'. World Shipping, 17(5). $10-11$. 